\title{
Mediating Effect of Fathers' Parenting Behavior on the Relationship Between Young Children's Temperament and Peer Play Behavior
}

\author{
Hee-Jin Yun ${ }^{1}$, Se-Jung Chun ${ }^{2}$, KyungOk Lee ${ }^{3}$ \\ Ph. D. Student, Department of Early Childhood Education, Duksung Women's University, Seoul, Republic of Korea ${ }^{1,2}$ \\ Professor, Department of Early Childhood Education, Duksung Women's University, Seoul, Republic of Korea ${ }^{3}$ \\ 유아 기질과 또래놀이행동의 관계에서 아버지 양육행동의 매개효과 \\ 윤희진 ${ }^{1}$, 천세정 $^{2}$, 이경옥 ${ }^{3}$ \\ 덕성여자대학교 유아교육학과 박사과정생 ${ }^{1,2}$, 덕성여자대학교 유아교육학과 교수 ${ }^{3}$
}

Objectives: Understanding peer play behaviors in young children is crucial because children's personal characteristics influence their peer play behaviors. In this study, we investigated the relationship between children's temperament ( 4 years old), fathers' parenting behavior ( 5 years old), and peer play behavior (6 years old) using longitudinal data from the Panel Study of Korean Children (PSKC). In addition, the mediating effect of fathers' parenting behavior on the relationship between children's temperament and peer play behavior was investigated.

Methods: A total of 1,070 children and their fathers were extracted for analysis from the Korean Children's Panel Study (PSKC) 2012 (Year 5) to 2014 (Year 7). The correlations between the relevant variables and the mediating effects of fathers' parenting behavior were analyzed using SPSS 25.0 and AMOS 25.0.

Results: Correlation analysis showed that children's emotionality and sociability were associated with fathers' parenting behavior, whereas their sociality and activity were associated with their play disturbance. Next, there was no mediating effect of fathers' warmth on the relationship between children's temperament and children's peer play interactions. The full mediating effects of the fathers' control on the relationship between the child's temperament (emotionality and sociability) and peer play behaviors such as disruption and disconnection were confirmed. Children's activity had a direct effect on their peer play interaction and disruption.

Conclusion: Peer play behavior revealed the importance of fathers' controlling parenting behaviors and children's temperament, especially in peer play disruption and disconnection. In particular, we confirmed the influence of father's controlling parenting behavior on children's sociability and emotionality temperament.

Keywords: temperament (EAS), father's parenting behavior, peer play behavior (PIPPS), play disruption, play disconnection, Panel Study of Korean Children (PSKC)

Corresponding Author: Kyung0k Lee, Professor, Department of Early Childhood Education, Duksung Women‘s University, 33, Samyang-ro 144gil, Dobong-gu, Seoul, Korea

E-mail: oaklee@duksung.ac.kr
(C)The Korean Association of Child Studies

This is an Open Access article distributed under the terms of the Creative Commons Attribution Non-Commercial License (http:// creativecommons.org/licenses/by-nc/4.0) which permits unrestricted noncommercial use, distribution, and reproduction in any medium, provided the original work is properly cited. 


\section{Introduction}

놀이는 유아가 세상을 경험하고 배우는 방식이다. 유아는 놀 이 속에서 또래와 규칙을 정하고 문제 상황을 해결하기 위해 상호작용한다. 2019 개정누리과정은 유아가 또래와 함께 놀 이하며 자신의 생각을 표현하거나 친구의 의견을 듣고 자신 과 다른 의견을 수용하고 조절하는 경험을 강조한다(Ministry of Education \& Ministry of Helath and Welfare, 2019). 놀이 중 심 교육과정을 운영하면서 유아의 또래놀이행동을 이해하 고 이를 긍정적인 방향으로 이끌어내기 위한 노력이 중요해 졌다. 유아는 놀이 속에서 또래와의 효과적인 상호작용에 필 요한 사회적, 정서적, 인지적, 언어적 능력을 발달시켜 나간다 (Hampton, Fantuzzo, \& Manz, 1999; J. W. Kim \& Lee, 2007). 유 아의 놀이는 유아기에 접어들면서 상호작용에 근거한 사회화 형태로 발전하며(O. B. Chung, 2002), 유아의 개별 특성에 따 라 다르게 나타나기 때문에 유아의 또래놀이행동을 이해하는 것이 매우 중요한 의미를 지닌다.

Fantuzzo 등(1995)은 또래놀이행동을 긍정적 측면인 놀이상 호작용(interaction)과 부정적 측면인 놀이방해(disruption), 놀이 단절(disconnection)로 구분하였다. 놀이상호작용은 유아가 놀 이에 몰입하고 놀이를 확장하도록 돕는 친사회적인 특성을 가 지는 반면, 부정적 측면인 놀이방해는 놀이에서 공격적이고 부 정적 정서를 표현하고, 놀이단절은 놀이 시 위축되거나 타인에 게 무시 또는 거부당하는 특징을 가지고 있으며 또래와의 놀이 에 참여하거나 놀이를 지속하는 것을 어렵게 한다. 또래놀이행 동 관련 연구들은 일반적으로 부정적인 측면인 놀이단절이나 놀이방해보다는 긍정적인 측면을 검증하는 연구로 놀이상호 작용 역량을 기르거나(Lim, 2018; Moon \& Ohm, 2009), 자유선 택활동 놀이상황에서 유아의 적극적이고 긍정적인 놀이상호 작용을 중심으로 이루어졌다(Moon \& Ohm, 2009). 그러나 또 래놀이행동은 또래와의 긍정적 상호작용(놀이상호작용)과 더 불어 또래의 놀이에 부적절하게 개입하거나(놀이방해) 또래에 의해 부적절하게 거부당하고 또래놀이 상황에서 위축되어있 는 놀이행동(놀이단절)을 독립적인 요소로 보고 있으며, 이러 한 놀이행동을 구분하여 살펴볼 필요가 있다.

또래놀이행동에 대한 아동패널연구(H. S. Hwang \& Suh, 2018; S. L. Kim \& Park, 2015)는 유아기 또래놀이행동은 연령 에 따라 다양한 양상으로 나타난다고 보고하였다. 만 3세 $(\mathrm{H}$. S. Hwang \& Suh, 2018)의 또래놀이행동은 놀이상호작용, 놀이 방해, 놀이단절의 평균이 모두 만 4세(S. L. Kim \& Park, 2015) 보다 높게 나타났다. 일반적으로 만 3세는 또래에게 관심을 보
이는 병행놀이가 주로 나타나는 시기이고, 만 4세는 사회적 놀 이가 발달하지만 조직적으로 또래와 상호작용하는 협동놀이 가 적절히 이루어지지 않는 시기이다. 만 4세 이후 유아는 언어 적 능력의 향상으로 또래와 협동놀이가 활발히 이루어져 또래 와의 놀이에서 보이는 긍정적, 부정적 또래놀이행동이 더 뚜렷 하게 나타나는 경향을 보인다(M.-R. Cho, 2007). 종합하면, 유 아기 또래놀이행동은 놀이에서의 대인관계를 나타내는 중요 한 변인이라고 볼 수 있다. 또한 유아의 연령이 증가할수록 사 회.인지적으로 성숙한 놀이에 참여하게 되므로(H. Lee \& Shin, 2014), 유아의 놀이행동이나 또래관계를 이해하는데 중요한 자료를 제공할 수 있을 것으로 기대된다. 유아의 또래놀이 발 달과정을 고려할 때, 놀이행동의 양상이 사회.인지적으로 성숙 한 만 6세를 중심으로 또래놀이행동을 검토할 필요가 있다.

유아의 또래놀이행동에 관한 선행연구를 살펴보면, 유아 의 개인적 변인 중 기질(H. S. Hwang \& Suh, 2018; E. O. Jo \& Choe, 2003; S. L. Kim \& Park, 2015; M. R. Lee, 2015; J. H. Lee \& Kim, 2012; Y. J. Song, 2017)과 부모 변인(W. Cho \& Kim, 2014; H. S. Hwang \& Suh, 2018; J. Song \& Lee, 2017; Y. J. Song, 2017; Suh, 2017) 관련 연구들이 주를 이룬다. 먼저 또래놀이행 동과 관련한 다양한 변인 중 기질은 유아의 개인적 특성이며 또래놀이행동을 예측하는 핵심적인 변인으로(Y.-S. Hwang \& Choi, 2007; W. Y. Park, Ma, \& Chon, 2004), 놀이성향을 예측하 는 설명력이 높다(E. O. Jo \& Choe, 2003). W. Kim, Kim, Lee와 $\mathrm{Nam}$ (2014)은 만 4세 유아의 기질 중 특히 정서성, 활동성 기 질이 놀이방해, 놀이단절과 같은 부정적 또래놀이행동을 이해 하는데 도움이 되므로 유아의 기질을 중요한 변인으로 살펴볼 필요가 있다고 주장하였다.

기질과 또래놀이행동에 관한 연구의 대부분은 아동패널연 구를 기초로 수행되었다. 아동패널연구에서는 행동을 조절 하는 요인으로 기질을 강조하며, 정서성(emotionality), 사회성 (sociability), 활동성(activity)으로 나누어 기질을 측정한 Buss와 Plomin (1984)의 Emotionality, Activity and Sosiability (EAS) 척 도를 사용하였다. 아동패널연구의 4차년도(만 3세) 연구(H. S. Hwang \& Suh, 2018)와 5차년도(만 4세) 연구(S. L. Kim \& Park, 2015)에서는 연령에 따라 유아의 기질과 또래놀이행동 의 관련성이 다르게 나타나고 있다. 만 3세의 경우, 기질 하위 척도 중 사회성이 긍정적 또래놀이행동(상호작용)과 정적 상 관을 보이고 부정적 또래놀이행동(단절, 방해)과 부적 상관을 보였다. 반면 정서성과 활동성은 긍정적 또래놀이행동(상호 작용)과 부적 상관을 보이고 부정적 또래놀이행동(단절, 방해) 과 정적 상관을 보였다(S. L. Kim \& Park, 2015). 만 4세의 경우 
(H. S. Hwang \& Suh, 2018), 기질 하위척도 중 사회성은 놀이 상호작용과 놀이방해에서 정적 상관을 보이고 놀이단절에서 는 부적 상관을 보인 반면, 정서성은 놀이단절과 부적 상관을 보이고 활동성은 놀이방해와 정적상관을 보였다. 아동패널연 구 이외에도 제주지역 만 4-5세 유아 217명을 대상으로 한 J. H. Lee와 Kim (2012)의 기질과 또래놀이행동에 대한 연구에서 는 기질 중 사회성이 놀이상호작용과 정적 상관을, 놀이단절 과 놀이방해는 부적 상관을 보고하고 있으며 이는 패널자료와 상이한 결과이다.

이러한 선행연구를 종합해 보면, 기질과 또래놀이행동 간 의 관련성이 유아의 연령에 따라 다양한 양상으로 나타나고, 기질 중 사회성과 정서성은 유아의 또래놀이행동과 깊이 연관 되어 있음을 알 수 있다. 또한 일반적으로 만 4-5세의 기질 중 사회성이 긍정적 또래놀이행동과 관련을 보이고, 정서성과 활 동성이 부정적 또래놀이행동과 관련이 있음을 확인하였다. 특 히 이러한 기질과 또래놀이행동의 관계는 놀이방해와 놀이단 절에서 두드러지게 나타난다. 연령별 기질과 또래놀이행동에 대한 결과는 앞서 지적한 유아기 놀이행동 발달과정으로 인해 일관된 결론을 도출하는 데 어려움이 있으며, 연령에 따라 유 아의 기질과 또래놀이행동의 관련성이 다르게 나타난다(S. L.

Kim \& Park, 2015). 뿐만 아니라 Magdalena (2015)는 유아의 또 래놀이행동에 기질이 실질적인 영향력을 나타내며, 강력한 예 측변인임을 밝혔다. 국내패널연구(S. L. Kim \& Park, 2015)에 서도 전반적인 유아기를 대상으로 기질과 또래놀이행동 간의 발달적 변화과정을 검증할 필요가 있다고 하였으며, 만 4세 대 상 Shin (2019)의 연구에서는 기질과 또래놀이행동 간의 인과 관계를 살펴보는 연구가 필요함을 제언하였다. 그러므로 발달 초기 유아의 기질 특성이 이후 유아의 또래놀이행동과 어떻게 연관되어 있는지 살펴볼 필요가 있다.

유아는 사회문화적인 맥락 내에서 능동적이고 적극적인 존재로 발달해간다(Miller, 2011). 부모는 유아가 태어나서 처 음 만나는 사람으로 유아의 발달에 있어 가장 영향력이 큰 존 재이다. 유아는 부모와의 관계에 따라 성격과 사회성 발달이 좌우되기도 하고(Y.-S. Chung, Kim, \& Park, 2001), 부모와의 상호작용이 유아의 발달에 변화를 주기도 한다(O. B. Chung, 2006). 유아의 또래놀이행동에 영향을 미치는 부모 변인으로 는 양육행동(Chung, Yee, \& Kang, 2017; I. Kim, 2017; K. S. Kim \& Park, 2002; S.-H. Lee, Lee, \& Park, 2019; J. Song \& Lee, 2017; Y. J. Song, 2017; Suh, 2017; Woo, 2016), 양육참여(C. R. Lee \& Moon, 2011; Yeon \& Choi, 2014), 양육태도(H.-R. Choi, Yoo, \& Kim, 2017; Yeon \& Choi, 2014) 등이 있다. 특히 부모의 양육행
동은 유아의 또래놀이행동과 밀접한 관련이 있다. Baumrind 의 이론적 모델에 근거한 부모의 양육행동은 온정과 통제 두 가지 요인으로 나누어 볼 수 있다. 온정적 양육행동은 부모가 자녀에게 애정과 관심을 표현하고 자녀의 독립성을 인정하고 자녀와의 의사소통 수준이 높은 양육행동이고, 통제적 양육행 동은 자녀에게 부모의 규칙과 기대에 따르도록 지도, 훈육하 고 성숙한 행동을 요구하며 부적절한 행동을 규제하는 양육행 동이다. 선행연구(Y. Kim, 2012; J.-Y. Park \& Lee, 2009)를 살펴 보면, 온정적 양육행동이 많이 나타날수록 유아의 사회적 자 발성이 높아져 놀이 시 또래와의 협력이나 협동활동이 증가하 고, 통제적 양육행동이 많이 나타날수록 유아의 신체적, 사회 적, 인지적 자발성이 높게 나타남을 알 수 있다.

최근 아버지가 자녀양육에 참여할 수 있는 출산휴가, 육아 휴직과 같은 제도가 마련되고(Rho, 2014), 아버지의 양육참여 를 지원하는 정책이 시행되고 있는 만큼 아버지 양육행동의 중요성이 조명되고 있다. 일반적으로 아버지 양육행동은 어린 연령보다는 유아기에 주된 영향력을 지닌다(J. H. Kim, 2017). 아버지 양육행동은 자녀의 행동을 형성하는데 있어 어머니 나 또래친구보다 더 실제적이고 직접적인 역할을 한다(Hur, 2006). 또한 아버지 양육행동은 주로 놀이를 중심으로 나타나 는 경향(Grossmann et al., 2002)이 높기 때문에 유아가 또래관 계를 형성하고 유지하기 위한 능력을 증가시키는 데 중요한 역할을 한다(Suh, 2017). I. Kim (2017)은 유아의 언어와 사회. 정서적 능력이 아버지의 양육행동과 관련이 있을 뿐만 아니라 43 개월 이후 자녀의 연령이 증가함에 따라 통제의 범위를 좁 히는 양육행동이 영유아 발달에 효과적이라고 하였다. 즉, 아 버지의 양육행동은 아동 발달 중 또래관계에 영향력이 있으며 (Suh, 2017; Yamagata, Nakamuro, \& Inui, 2013), 아버지의 놀이 성이 양육행동을 통해 유아에게도 영향을 미치므로(K. S. Kim $\&$ Park, 2002), 유아의 또래놀이행동과 관련하여 아버지 양육 행동을 살펴볼 필요가 있다(Chung, Yee, \& Kang, 2017).

아동패널연구 7차년도(만 6세) 자료를 사용한 S.-H. Lee 등 (2019)의 연구에서는 부모의 온정적 양육행동과 긍정적 또래 놀이행동의 관련성을 보고하였다. 7차년도(만 6세) 유아의 사 회적 기술을 매개로 한 부모 양육행동과 또래놀이행동에 대 한 선행연구(J. Song \& Lee, 2017)에서는 어머니의 온정적, 통 제적 양육행동과 또래놀이행동 간의 관계가 유의하지 않았지 만, 아버지 온정적 양육행동은 놀이상호작용과 정적 상관을 보이고, 놀이단절과 부적 상관이 나타났다. 또한 5 차년도(만 4 세) 자료를 사용한 연구(Woo, 2016)에서는 아버지 양육행동 이 중요한 역할을 하고 있음을 강조하였다. 즉, 만 4세 유아의 
발달에 있어 아버지 양육행동이 효과적으로 작용하고 있으며 (Woo, 2016), 만 6세 아버지의 온정적 양육행동과 유아 놀이상 호작용의 연관성(J. Song \& Lee, 2017)을 통해 만 5-6세 시기 아 버지와 원활한 상호작용이 이루어짐을 알 수 있다. 이에 만 5 세 유아의 아버지 양육행동과 만 6세 유아의 또래놀이행동이 어떻게 관련되어 있는지를 검토한다면 유아의 또래놀이행동 에 대한 아버지 양육행동의 중요성을 이해하는 데 있어 의미 있는 자료가 되리라고 본다.

I. Kim (2017)은 유아의 사회정서적 발달을 도모하는데 있어 부모역할이 중요하며, 부모가 자신의 양육행동과 자녀가 보이 는 발달상의 문제를 관련지어 따뜻함과 단호함을 상황에 맞게 조화롭게 드러내야 한다고 하였다. Suh (2017)는 온정적 양육 행동과 통제적 양육행동은 서로 다른 메커니즘으로 작동한다 고 보았다. 특히 통제적 양육행동은 자녀의 자유를 허용하지만 행동을 제한할 때에는 그 이유를 설명하고 융통성 있는 방법을 적용하는 것으로, 자녀의 요구와 의견에 관심을 기울이고, 자 녀의 수준 및 자녀가 자신의 행동을 통제할 수 있는 능력에 맞 추는 양육방법이다(K. Choi \& Song, 2010). 표현적 기능을 지닌 어머니는 자녀를 돌보고 정서적 욕구를 충족시켜주는 역할을 하는 데 반해, 아버지는 아동의 행동을 통제하고 그 사회에 맞 는 가치와 태도 그리고 행동을 습득하는 가치의 판단자로서 도 구적 역할을 하는 것으로 간주된다(B. Cho, 2006). 또한 아버지 는 어머니에 비해 자녀양육에는 덜 참여하지만 놀이활동에는 더 많은 시간을 보내는데, 자녀는 아버지로부터 사회적 적응 의 훈련을 받아 친구관계를 맺어가는 방향을 제시받는다(O. B. Chung \& Chung, 2019). 이와 같이 아버지의 양육행동은 유아 의 또래놀이행동을 이해하는 중요한 요소이다. 따라서 유아의 기질과 또래놀이행동에서 아버지의 통제적, 온정적 양육행동 의 매개적 기능을 구체적으로 살펴봄으로써 아버지 양육행동 이 어떻게 작용하는지를 밝힐 필요가 있다.

만 3세(4차년도) 대상 패널연구(W. Cho \& Kim, 2014)에서 는 유아의 기질 중 정서성과 아버지의 사회적 양육방식이 긍정 적 또래놀이행동인 놀이상호작용을 형성하고 유지하는데 긍 정적 영향을 미치는 것으로 나타났다. 그러나 부정적 또래놀 이행동인 놀이방해는 기질 중 사회성과 정서성이 정적 영향을, 놀이단절은 기질 중 정서성과 활동성이 정적 영향을 주었으 며, 아버지의 사회적 양육방식은 놀이방해와 놀이단절을 감소 시키는 것으로 확인되었다. 선행연구(W. Cho \& Kim, 2014)는 만 3세 유아를 대상으로 살펴보았으므로, 본 연구에서는 유아 의 기질과 또래놀이행동과의 관계에서 아버지 양육행동의 영 향력이 극대화되는 만 5 세의 아버지 양육행동을 매개변인으로
선정하였다. 구조방정식 모형에 기초한 매개효과 분석결과는 단순 상관분석 결과와 상이할 수 있으며, 직접효과와 간접효과 가 충돌하여 나타나는 억제효과와 가장효과를 확인할 수 있을 것으로 기대된다(H. -H. Kim \& Kim, 2020; K. Lee, 2021).

이상의 선행연구들을 종합해 보면, 유아의 기질과 아버지 양육행동, 또래놀이행동의 관계에 대한 연구가 수행되었으 나, 본 연구에서는 5-7차년도 아동패널 종단데이터를 활용하 여 만 6세 또래놀이행동에 대한 만 4세 기질과 만 5세 아버지 양육행동의 상관관계를 살펴보고, 만 4세 기질과 만 6세 또래 놀이행동의 관계에서 만 5세 아버지 양육행동의 매개효과를 살펴보았다. 특히 만 4세 유아의 기질과 유아기 또래놀이행동 이 안정화되는 만 6세에 나타난 또래놀이행동의 관계에서 만 5 세의 아버지 양육행동의 매개효과를 검토함으로써 아버지 양육행동의 중요성을 이해하는 데 중요한 자료가 될 것으로 기대된다. 이를 위해 다음과 같은 연구문제를 설정하였으며, Figure 1에 연구모형을 제시하였다.

\section{연구문제 1}

유아기질, 아버지 양육행동, 또래놀이행동 간의 관계는 어떠한가?

\section{연구문제 2}

유아기질과 또래놀이행동의 관계에서 아버지 양육행동의 매 개효과는 어떠한가?

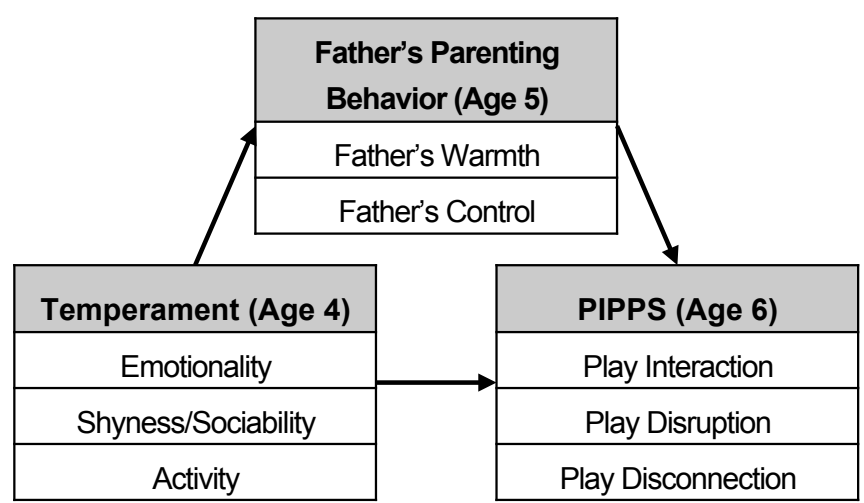

Figure 1. The hypothesized model.

\section{Methods}

\section{연구대상}

본 연구에서는 유아기질, 아버지 양육행동, 또래놀이행동의 
관계를 살펴보기 위하여, 육아정책연구소(Korea Institute of Childcare and Education [KICCE]) 한국아동패널(Panel Study of Korean Children [PSKC])의 5-7차년도(2012-2014년) 자료를 사 용하여, 5 차년도 만 4 세 유아의 기질, 6차년도 아버지의 양육 행동, 7 차년도 만 6 세 유아의 또래놀이행동을 추출하여 분석 하였다. 차수별로 무응답이 있는 경우를 제외한 후, 총 1,070 가구의 자료를 분석에 사용하였다. 분석 대상 유아의 평균 월 령은 5차년도 기준으로 $50.99(S D=1.20)$ 개월이었다. 유아의 성별은 남아 558명(52.1\%), 여아 512명(47.9\%)으로 구성되었 으며, 출생순위는 첫째 491명(45.9\%), 둘째 457명(42.6\%), 셋 째 이상 123 명(11.6\%)이었다. 아버지의 연령과 최종학력은 6 차년도 기준으로 무응답 3명을 제외한 아버지의 연령은 30대 미만 8명(.8\%), 30대 643명(60\%), 40대 이상 416명(39\%)이었 으며, 최종학력은 고졸 이하 295명(27.6\%), 전문대졸 222명 (20.7\%), 4년제졸 449명(42.0\%), 대학원졸 101명(9.4\%), 무응 답 3 명 $(.3 \%)$ 이었다.

\section{연구도구}

\section{유아기질(EAS)}

유아의 기질은 Buss와 Plomin (1984)이 개발한 EAS 척도를 Mathiesen과 Tambs (1999)가 타당화하고 한국아동패널 연구진 이 번역한 척도를 이용해 조사되었다. 본 척도는 아동이 부정 적인 정서를 많이 나타내는 정서성(5문항), 아동이 타인과 잘 어울리며 덜 수줍어하는 사회성(10문항), 아동이 움직이길 좋 아하고 활동적인 특성을 지니는 활동성(5문항)의 3 개 하위영 역으로 구성되며, 전혀 그렇지 않다(1점)부터 매우 그렇다(5 점)로 구성된 5점 Likert 척도를 사용하여 측정되었다. 본 연구 에서는 한국아동패널 5차년도(2012년) 자료 중 어머니가 평정 한 자료를 사용하였으며, 하위영역의 항목-전체 상관관계 값 을 참고하여 사회성에서 19번(Cronbach's $\alpha=.069$ ) “우리 아이 는 혼자 있을 때면 외로워한다.”를 삭제하였다. 본 연구의 내 적합치도(Cronbach's $\alpha$ )는 정서성 .736 , 사회성 .860 , 활동성 .762 이었다.

\section{아버지 양육행동}

아버지 양육행동은 B. Cho 등(1999)의 문항을 참고하여 한국 아동패널 연구진이 자체 제작한 부모 양육행동 척도를 이용해 조사되었다. 부모가 자녀에게 애정과 관심을 표현하고 자녀의
독립성을 인정하고 자녀와의 의사소통 수준이 높은 온정적 양 육행동(6문항)과 자녀에게 부모의 규칙과 기대에 따르도록 지 도, 훈육하고 성숙한 행동을 요구하며 부적절한 행동을 규제 하는 통제적 양육행동( 6 문항) 2 개의 하위영역으로 구성되며, 전혀 그렇지 않다(1점)부터 매우 그렇다(5점)로 구성된 5점 Likert 척도를 사용하여 측정되었다. 본 연구에서는 한국아동 패널의 6차년도(2013년)에 유아의 아버지에 의해 응답된 자료 를 사용하였다. 본 연구의 내적합치도(Cronbach's $\alpha$ )는 온정적 양육행동 .808 , 통제적 양육행동 .880 이었다.

\section{또래놀이행동}

유아의 또래놀이행동은 Fantuzzo 등(1998)이 개발한 또래놀이 행동척도(Penn Interactive Peer Play Scale [PIPPS])를 H. Y. Choi 와 Shin (2008)이 타당화한 내용을 참고하여 한국아동패널 연 구진이 검토/수정하여 예비조사 실시 후 문항을 확정한 척도 를 사용하여 조사되었다. 본 척도는 친사회적인 특성과 놀이 를 순조롭게 이어가는 특성인 놀이상호작용(9문항), 공격적이 고 부정적인 정서표현인 놀이방해(13문항), 위축되거나 타인 에게 무시 또는 거부당하는 특징인 놀이단절(8문항)의 3 개 하 위영역으로 구성되었으며, 전혀 그렇지 않다(1점)부터 항상 그렇다(4점)로 구성된 4점 Likert 척도를 사용하여 측정되었 다. 본 연구에서는 한국아동패널 7차년도(2014년) 자료 중 교 사가 평정한 자료를 놀이상호작용, 놀이단절, 놀이방해의 하 위요인별 평균점수를 사용하였으며, 각 점수가 높을수록 하 위요인별 행동을 많이 보임을 의미한다. 하위영역의 항목-전 체 상관관계 값을 참고하여 놀이방해에서 상대적으로 낮은 역 채점 문항 14 번(Cronbach's $\alpha=-.055)$ “친구들에게 싸우지 않 고 반대 의견을 말한다.”를 삭제하였다. 본 연구의 내적합치도 (Cronbach's $\alpha$ )는 놀이상호작용 .799, 놀이방해 .898, 놀이단절 .888 이었다.

\section{자료분석}

본 연구는 SPSS 25.0 (IBM Co., Armonk, NY)와 AMOS 25.0 (IBM Co., Armonk, NY)프로그램을 이용하여 자료를 분석하 였으며, 먼저 SPSS 25.0으로 연구대상의 일반적 특성을 확인 하기 위하여 아버지와 유아의 사회인구학적 요인에 관한 빈 도분석 및 기술통계를 수행하였다. 다음으로 측정도구의 신 뢰도 검증을 위한 문항 내적합치도 계수를 산출하였다. 첫째, 유아기질(정서성, 사회성, 활동성), 아버지 양육행동(온정, 통 
Table 1

Correlations of EAS, Father's Parenting Behavior, and PIPPS

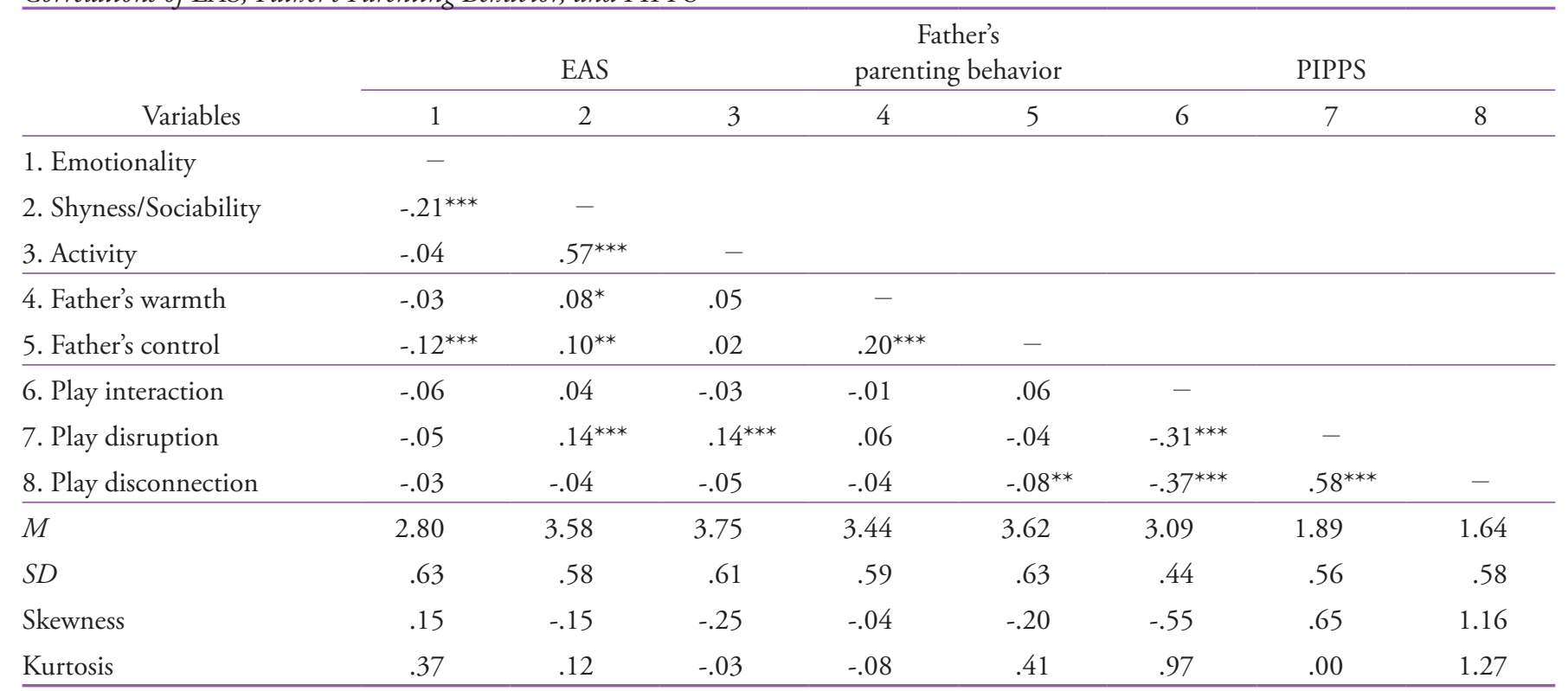

$N=1070$.

${ }^{* * *} p<.01$.

제), 또래놀이행동(놀이상호작용, 놀이방해, 놀이단절)의 관 계를 살펴보기 위하여 Pearson의 상관관계분석을 실시하였 다. 둘째, 유아기질(정서성, 사회성, 활동성)과 또래놀이행동 (놀이상호작용, 놀이방해, 놀이단절) 간의 관계에 있어 아버지 양육행동(온정, 통제)의 직.간접적 매개효과를 확인하기 위해 AMOS 25.0 프로그램을 이용하여 구조방정식 모형(Structural Equation Modeling [SEM])분석을 수행하였다.

\section{Results}

\section{유아기질, 아버지 양육행동, 또래놀이행동 간의 관계}

유아기질(EAS), 아버지 양육행동(father's parenting behavior), 또래놀이행동(PIPPS) 간의 상관관계를 분석한 결과, Table 1 과 같이 유아기질 중 정서성은 아버지의 통제적 양육행동과 통계적으로 유의한 부적 상관 $(r=-.12, p<.001)$ 을 보였다. 반 면, 유아기질 중 사회성은 아버지의 온정적 양육행동 $(r=.08, p$ $<.05)$ 과 통제적 양육행동 $(r=.10, p<.01)$ 이 정적으로 유의한 상관을 보였다. 유아의 기질 중 사회성 $(r=.14, p<.001)$ 과 활 동성 $(r=.14, p<.001)$ 은 놀이방해와 통계적으로 유의한 상관 을 보였다. 아버지의 통제적 양육행동은 놀이단절 $(r=-.08, p<$ .01)과 통계적으로 유의한 상관을 보였다.

\section{유아 기질과 또래놀이행동의 관계에서 아버지 양육행동의 매개효과}

기질(만 4세)과 또래놀이행동(만 6세) 간의 관계에서 아버지 양육행동(만 5세)의 매개효과를 살펴보았으며, 또래놀이행동 의 가설모형의 적합도 지수는 $\chi^{2}(76)=213.694, p=.000$ 이고, $\mathrm{GFI}=.976, \mathrm{NFI}=.975, \mathrm{TLI}=.974, \mathrm{CFI}=.984, \mathrm{RMSEA}=.041$ 로 적합하였다. 유아의 기질과 또래놀이행동에서 아버지 양육 행동의 매개효과를 검증하기 위하여 가설모형에 기초한 직·간 접 효과 분석을 실시한 결과는 Figure 2, Table 2와 같다.

먼저, 아버지 양육행동의 매개효과를 살펴보면, 만 4세 유 아의 기질 중 정서성과 사회성은 만 5세 아버지의 통제적 양육 행동을 매개로 만 6 세의 놀이방해 $(\beta=-.075, p<.05)$ 와 놀이단 절 $(\beta=-.087, p<.05)$ 에 이르는 경로가 유의하였다. 특히 정서 성의 경우 만 5 세 아버지의 통제적 양육행동이 부적 상관 $(\beta=$ $-.126, p<.001)$ 을 보였으나, 사회성은 만 5 세 아버지의 통제적 양육행동이 정적 상관 $(\beta=.125, p<.05)$ 을 보였다. 유아의 정 서성과 사회성은 또래놀이행동에 이르는 직접 경로는 유의하 지 않아 아버지의 통제적 양육행동은 만 4세의 정서성 및 사회 성과 만 6세의 놀이방해 및 놀이단절 간의 관계에서 완전매개 효과를 나타내었다. 반면 아버지의 온정적 양육행동을 매개로 한 경로는 유의하지 않아 아버지의 양육행동 중 통제적 양육 행동만이 매개역할을 함을 알 수 있다. 


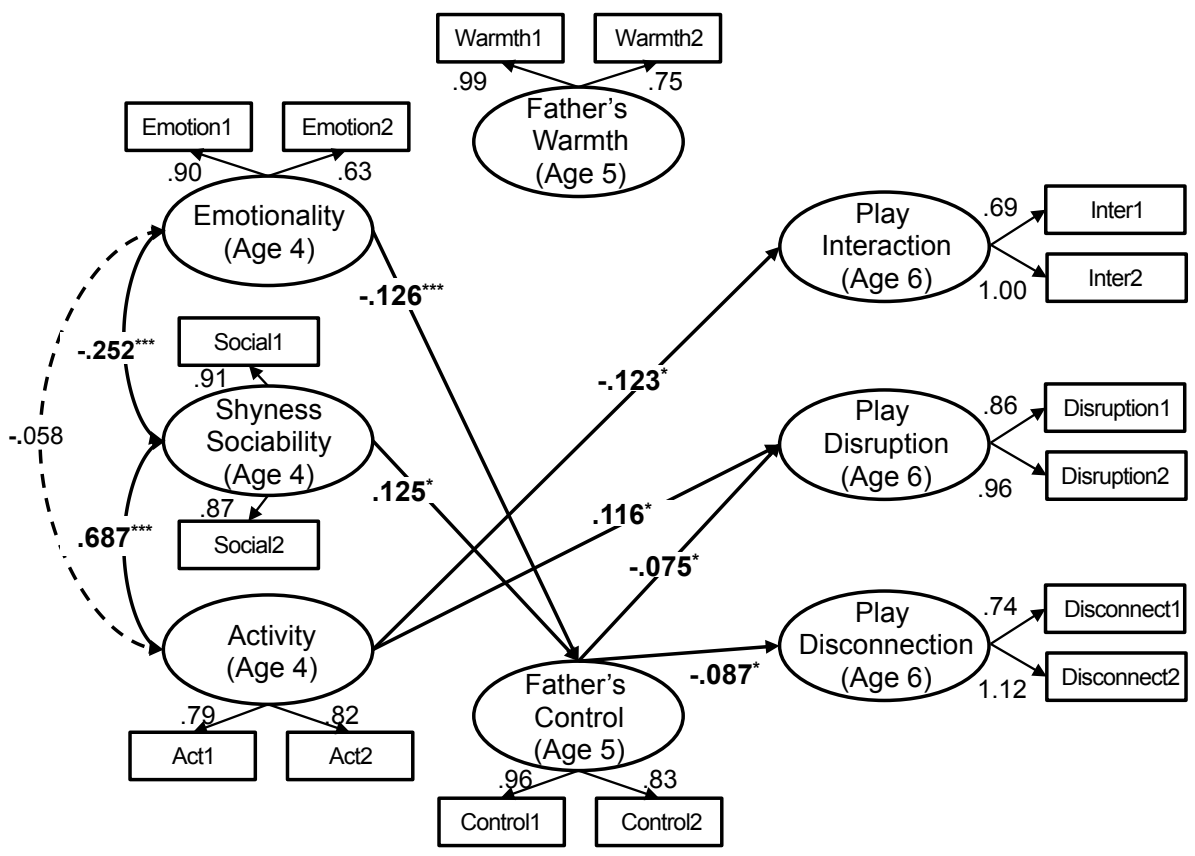

Figure 2. PIPPS structural model pathway coefficients.

${ }^{*} p<.05 .{ }^{* *} p<.01 .{ }^{* * *} p<.001$.

Table 2

Path Coefficient and Direct/Indirect Effects of the PIPPS Structural Model

\begin{tabular}{|c|c|c|c|c|c|c|c|}
\hline & & & & & & $\beta$ & \\
\hline & Var & & $S E$ & $\mathrm{CR}$ & Direct & Indirect & Total \\
\hline Emotionality & $\rightarrow$ & Father's warmth & .052 & -.575 & -.023 & & -.023 \\
\hline & $\rightarrow$ & Father's control & .053 & -3.271 & $-.126^{* * *}$ & & $-.126^{* * *}$ \\
\hline & $\rightarrow$ & Play interaction & .040 & -1.012 & -.039 & -.004 & -.043 \\
\hline & $\rightarrow$ & Play disruption & .039 & -.983 & -.037 & .008 & -.029 \\
\hline & $\rightarrow$ & Play disconnection & .049 & -1.270 & -.049 & $.011^{*}$ & -.037 \\
\hline Shyness/Sociability & $\rightarrow$ & Father's warmth & .063 & 1.579 & .093 & & .093 \\
\hline & $\rightarrow$ & Father's control & .063 & 2.118 & $.125^{*}$ & & $.125^{*}$ \\
\hline & $\rightarrow$ & Play interaction & .048 & 1.803 & .103 & .002 & .105 \\
\hline & $\rightarrow$ & Play disruption & .047 & 1.313 & .074 & -.003 & .070 \\
\hline & $\rightarrow$ & Play disconnection & .060 & .337 & .019 & -.013 & .007 \\
\hline Activity & $\rightarrow$ & Father's warmth & .058 & -.319 & -.019 & & -.019 \\
\hline & $\rightarrow$ & Father's control & .058 & -1.225 & -.070 & & -.070 \\
\hline & $\rightarrow$ & Play interaction & .045 & -2.135 & $-.123^{*}$ & -.002 & $-.125^{*}$ \\
\hline & $\rightarrow$ & Play disruption & .043 & 2.046 & $.116^{*}$ & .004 & $.120^{*}$ \\
\hline & $\rightarrow$ & Play disconnection & .055 & -1.360 & -.078 & .006 & -.072 \\
\hline Father's warmth & $\rightarrow$ & Play interaction & .028 & -.890 & -.032 & & -.032 \\
\hline & $\rightarrow$ & Play disruption & .028 & 1.880 & .067 & & .067 \\
\hline & $\rightarrow$ & Play disconnection & .035 & -.496 & -.018 & & -.018 \\
\hline Father's control & $\rightarrow$ & Play interaction & .027 & 1.134 & .040 & & .040 \\
\hline & $\rightarrow$ & Play disruption & .027 & -2.144 & $-.075^{*}$ & & $-.075^{*}$ \\
\hline & $\rightarrow$ & Play disconnection & .034 & -2.416 & $-.087^{*}$ & & $-.087^{*}$ \\
\hline
\end{tabular}

${ }^{*} p<.05 .{ }^{* *} p<.01 .{ }^{* * *} p<.001$. 
다음으로, 만 4세 유아의 활동성은 만 6세 놀이상호작용과 놀이방해에 이르는 직접 경로만 유의하였으며, 만 5세 아버지 양육행동(온정적, 통제적)의 매개효과는 나타나지 않았다. 활 동성과 놀이상호작용의 경우 부적상관 $(\beta=-.123, p<.05)$ 을 보 였으나, 놀이방해는 정적상관 $(\beta=.116, p<.05)$ 이 나타났다.

\section{Discussion}

본 연구는 한국아동패널 5-7차년도(2012-2014년) 종단적 자료 를 이용하여 만 4 세 유아의 기질, 만 5세 유아의 아버지 양육 행동, 만 6 세 유아의 또래놀이행동과 어떠한 관계가 있는지 살 펴보고, 만 4세 유아의 기질과 만 6세 유아의 또래놀이행동에 서 만 5세 유아의 아버지 양육행동의 매개효과를 검토하였다. 본 연구의 주요 결과를 요약하고 논의하면 다음과 같다.

첫째, 유아의 기질, 아버지 양육행동의 관계를 살펴보면, 만 4세 유아의 높은 정서성은 1 년 뒤 아버지 통제적 양육행동 의 감소와 관련이 있었으며, 만 4 세 유아의 높은 사회성은 1 년 뒤 아버지 온정적, 통제적 양육행동의 향상과 관련이 있었다. 이와 같은 연구결과는 영아(0-2세)의 정서성이 낮을수록 유아 기 아버지 온정적 양육행동이 낮게 나타난 Jang과 Kim (2018) 의 연구와 다른 결과로, 영아기와 유아기 기질에 따른 아버 지 양육행동의 차이를 유추해 볼 수 있다. 또한 유아의 기질 과 또래놀이행동의 관계에서는 만 4 세 사회성과 활동성이 높 은 유아의 만 6세 놀이방해가 증가하는 것으로 나타났다. 이 는, 만 3세 유아의 활동성이 놀이방해와 정적 상관을 보인 $\mathrm{H}$. S. Hwang과 Suh (2018)의 연구와, 만 4세 유아의 사회성과 활 동성이 놀이방해와 정적상관을 보인 S. L. Kim과 Park (2015) 연구와 일치하는 결과이다. 이와 같은 연구결과에 기초해보면 만 4세 유아의 기질 중 정서성과 사회성은 만 5 세 아버지의 양 육행동, 특히 통제적 양육행동과 관련이 있으며, 만 4세 유아 의 기질 중 사회성과 활동성은 만 6세 또래놀이행동 중 놀이방 해와 관련이 있음을 알 수 있다.

둘째, 유아의 기질과 또래놀이행동에서 아버지 온정적 양 육행동의 매개효과는 나타나지 않았으나, 만 5 세 아버지 통제 적 양육행동은 유아의 만 4세 정서성, 사회성과 만 6세 놀이방 해, 놀이단절의 관계에서 완전매개 역할을 하는 것으로 나타 났다. 이는 부정적인 정서를 보이는 만 4세 유아에게는 만 5세 아버지의 규칙과 기대에 따르도록 지도 훈육하고 부적절한 행 동을 규제하는 통제적 양육행동이 줄어들고, 이로 인해 만 6세 때 유아의 놀이방해와, 놀이단절이 증가하는 경향이 나타나는
것으로 해석된다. 반면 타인과 잘 어울리고 덜 수줍어하는 사 회성이 높은 만 4세 유아에게는 만 5 세 아버지가 규칙과 기대 에 따르도록 지도 훈육하고 부적절한 행동을 규제하는 양육 행동을 보일수록 만 6 세 유아의 놀이방해와 놀이단절이 줄어 드는 경향이 나타남을 알 수 있다. 종합하면, 아버지의 통제적 양육행동이 유아의 기질 중 사회성, 정서성과 또래놀이행동 의 부정적인 요인(놀이방해, 놀이단절)에 있어서 중요한 매개 변인임을 알 수 있다. 특히 만 5세 아버지의 통제적 양육행동 을 매개변수로 한 간접경로는 유의하였으나 직접경로는 유의 하지 않았다. 즉 아버지의 통제적 양육행동을 매개변수로 하 여 사회성 기질과 놀이방해 간의 상관은 가장된 관계(spurious relationship)가 존재함을 알 수 있다.

이를 통해 아버지의 통제적 양육행동이 유아의 기질 중 사 회성, 정서성과 또래놀이행동의 부정적인 요인(놀이방해, 놀 이단절)에 있어서 중요한 매개변인임을 확인하였다. 이는 아 버지 양육행동이 유아의 또래관계에 영향력을 미친다는 선행 연구(Suh, 2017; Yamagata et al., 2013)와 맥을 같이한다. 그러나 자녀의 연령이 증가함에 따라 통제의 범위를 좁히는 양육행동 이 발달에 효과적이라는 선행연구 결과(I. Kim, 2017)와 달리 자녀의 정서성과 사회성에 따라 규칙과 기대에 따르게 지도, 훈육하며 성숙한 행동을 요구하고 부적절한 행동을 규제하는 만 5세 아버지의 통제적 양육행동은 만 6세 놀이방해나 놀이 단절과 같은 부정적 또래놀이행동에 결정적인 역할을 하는 중 요한 요소임을 알 수 있다. 특히 정서성이 높은 유아는 놀이단 절이 증가한다는 선행연구(J. H. Lee \& Kim, 2012)와 사회성 이 높은 유아일수록 놀이방해와 놀이단절이 감소한다는 선행 연구(H. S. Hwang \& Suh, 2018; S. L. Kim \& Park, 2015; M. R. Lee, 2015; W. Y. Park et al., 2004; Y. J. Song, 2017)는 본 연구의 결과를 부분적으로 지지한다. 그러나 어머니 양육행동을 살펴 본 Kang과 Lee (2011)의 연구에서는 유아의 정서성과 어머니 의 온정적 양육행동은 부적상관을 통제적 양육행동은 정적상 관을 보였을 뿐만 아니라 사회성과 어머니의 통제적 양육행동 에서 부적상관을 보여, 아버지 양육행동을 대상으로 한 본 연 구와 상반된 결과임을 알 수 있다. 이를 통해 아버지와 어머니 의 양육행동은 유아의 기질에 따라 다르게 작용하면서 유아의 또래놀이행동에 관여하는 것으로 해석할 수 있다. 그러므로 만 5세 시기 아버지의 적절한 통제적 양육행동은 이후 만 6세 유아의 놀이방해와 놀이단절을 감소시키는 주요한 요인이 될 수 있으리라고 생각된다.

반면에 기질 중 활동성과 또래놀이행동 관계에서 아버지 양육행동의 매개효과는 없었으며, 유아의 활동성 기질은 놀이 
상호작용과 놀이단절에 직접적 효과를 나타냈다. 이는 활동 적인 특성을 가진 만 4세 유아는 만 6세 시기 놀이를 순조롭게 이어가는 놀이상호작용이 감소하고, 공격적이고 부정적인 정 서표현을 보이는 놀이방해가 증가하는 것으로 볼 수 있다. 이 는 기질을 통해 놀이성향을 예측할 수 있다는 연구결과(Y.-S. Hwang \& Choi, 2007; E. O. Jo \& Choe, 2003)를 부분적으로 지 지하며, 활동성이 높은 유아(49-54개월)가 또래활동에서 방해 가 되는 행동이 나타난다는 선행연구(Y. J. Song, 2017; W. Kim et al,. 2014)와 유아의 높은 활동성이 긍정적 또래놀이행동(상 호작용)과 부적 상관을 보인다는 연구결과(H. S. Hwang \& Suh, 2018)와 일치한다. 그러나 유아의 활동성과 놀이단절이 정적 상관을 보인다는 선행연구(H. S. Hwang \& Suh, 2018; S. L. Kim \& Park, 2015)와 달리, 본 연구에서는 유아의 활동성 기 질이 놀이 시 위축되거나 타인에게 무시, 거부당하는 놀이단 절에 이르는 직접적인 효과가 나타나지 않았다.

본 결론을 바탕으로 살펴보면 첫째, 유아 개인적 변인인 기 질이 환경적 변인인 아버지 양육행동(O. B. Chung, 2006)을 통 해 정서적 안정감을 가지게 되고, 또래와의 놀이에서 행위를 주도하거나, 협동을 통해 성장한다(Lasley, 2007/2012). 특히 기 질 중 정서성과 사회성이 아버지의 통제적 양육행동을 통해 놀이방해와 놀이단절에 영향을 미친다는 본 연구결과는 아버 지 양육의 중요성을 강조한다. 또한 기질과 어머니 양육행동 을 살펴본 선행연구(Kang \& Lee, 2011)와 상반된 결과를 통해 아버지가 자녀의 기질을 이해하는 것이 필요함을 확인하였다. 시대적 변화에 따라 아버지의 놀이효과는 강조되고 아버지의 놀이 참여가 증가하고 있으나 대부분의 아버지는 양육에 대한 이해가 부족하고 자신이 없어 놀이 또는 양육에 참여하는 것 을 어렵다고 생각하는 경우가 많다(J. Kim, 2017). 따라서 유아 기 자녀를 둔 아버지에게 자녀의 기질을 이해할 수 있는 기회 를 제공하고, 이에 따라 적절한 아버지의 통제적 양육행동이 이루어지도록 지원한다면 이후 유아의 놀이단절이나 놀이방 해와 같은 부정적 또래놀이행동을 통제하는데 긍정적인 역할 을 할 수 있을 것으로 기대된다.

둘째, 아버지의 온정적 양육행동과 달리 통제적 양육행동이 부정적 또래놀이행동(놀이방해, 놀이단절)에 영향을 주는 만 큼, 바람직한 양육행동을 위한 아버지 교육이 필요함을 시사한 다. 현재 육아문화 개선을 위한 정책과 제도 측면에서 예비부 모교육을 위한 대학 필수교양과목으로 지정해야 한다는 의견 이 제시되고 있으며, 육아 관련 소통의 장이 필요하며 육아 당 사자들의 의견을 개진할 수 있는 창구가 요구되고 있다(Kwon, Moon, \& Kim, 2019). 서울 유아교육진흥원의 학부모 교육원
에서는 학부모의 자녀교육 역량을 강화하기 위해 올바른 양육 행동, 자녀와의 의사소통 방법(C. Park, Kim, \& Choi, 2018)을 교육하는 등 사회의 변화에 따라 가정의 양육을 돕고 있다. 본 연구결과도 또래관계를 형성하고 유지하는 능력을 발달시키 는 만 4세 유아에게 아버지가 더 큰 영향력을 줄 수 있다는 Suh (2017)의 주장과 마찬가지로 아버지 양육행동에 대한 올바른 이해를 도울 수 있는 연구와 지원이 필요함을 시사한다.

이러한 연구 결과를 근거로 향후 연구를 위한 제언을 하면 다음과 같다. 첫째, 본 연구에서는 유아의 성별을 구분하여 살 펴보지 않았다. 그러므로 향후 연구에서는 유아의 성별을 구 분하여 아버지 양육행동과 또래놀이행동의 영향력을 살펴볼 필요가 있다. 둘째, 본 연구는 만 4세 기질, 만 5세 양육행동, 만 6세 또래놀이행동의 특성이 가장 극명하게 드러나는 시점 들을 추출 후 구조방정식 모형을 활용하여 살펴보았으나 이후 연구에서는 해당되지 않는 변인들의 부분을 통제하고 분석하 거나, 자기회귀교차지연모형을 활용한다면 변인의 자세한 영 향력을 알 수 있을 것이다.

\section{Acknowledgements}

This study was supported by the 2021 research grant of Duksung Women's University.

\section{Notes}

This article was presented at the 2021 Annual Spring Online Conference of the Korean Association of Child Studies.

\section{Conflict of Interest}

No potential conflict of interest relevant to this article was reported.

\section{References}

\section{In English}

Buss, A. H., \& Plomin, R. (1984). Temperament: Early developing 
personality traits. Hove, East Sussex: Psychology Press.

Fantuzzo, J., Sutton-Smith, B., Coolahan, K. C., Manz, P. H., Canning, S., \& Debnam, D. (1995). Assessment of preschool play interaction behaviors in young low-income children: Penn interactive peer play scale. Early Childhood Research Quarterly, 10(1), 105-120. doi:10.1016/08852006(95)90028-4

Grossmann, K., Grossmann, K. E., Fremmer-Bombik, E., Kindler, H., Scheuerer-Englisch, H., \& Zimmermann, P. (2002). The uniqueness of the child-father attachment relationship: Fathers' sensitive and challenging play as a pivotal variable in a 16-year longitudinal study. Social Development, 11(3), 301-337. doi:10.1111/1467-9507.00202

Hampton, V. R., Fantuzzo, J. W., \& Manz, P. H. (1999). Assessing interactive play in early childhood: Penn interactive peer play scale. NHSA Dialog A Research-to-Practice Journal for the Early Intervention Field, 3(1), 70-72. doi:10.1207/ s19309325nhsa0301_8

Magdalena, S. M. (2015). Study on the temperament as a predictor of peer interactions at preschool ages. Social and Behavioral Sciences, 187, 663-667. doi:10.1016/j.sbspro.2015.03.123

Miller, P. H. (2011). Theories of developmental psychology (5th ed.). New York: Worth Publishers.

Yamagata, S., Nakamuro, M., \& Inui, T. (2013). Inequality of opportunity in japan: A behavioral genetic approach. RIETI Discussion Paper Series 13-E-097. Retrieved August 3, 2021, form https://www.rieti.go.jp/en/

\section{In Korean}

Cho, B. (2006). Child development. Paju, Gyeonggi: Kyoyookbook. Cho, M.-R. (2007). The effects of cooperation game on young children's language ability and the quality of peer interaction (Master's thesis). Retrieved from http://www.riss.kr/ link?id=T10868737

Cho, W., \& Kim, E. (2014). Predicting young children's peer interactions from temperament and parenting styles. Korean Journal of Child Care and Education Policy, 8(2), 155-174.

Choi, H.-R., Yoo, J.-A., \& Kim, S.-M. (2017). Relationship among parenting style, mother-child interaction, young children's interactive peer play and problem behaviors by mother's employment status. The Journal of the Korea Contents Association, 17(3), 15-30. doi:10.5392/ JKCA.2017.17.03.015

Choi, K., \& Song, H. (2010). Baldalsimlihag jeon saeng-ae: Adong.cheongsonyeon-seong-in [발달심리학 전 생애: 아동. 성인·청소년]. Paju, Gyeonggi: Gyomoonsa.

Chong, Y.-S., Kim, Y. H., \& Park, B.-H. (2001). Child development and parental education. Seoul: Sigma Press.
Chung, M., Yee, B., \& Kang, S. (2017). The effect of father's playfulness on children's creative behavior: The mediated effect of father's parenting behavior and playfulness of the children. Korean Journal of Early Childhood Education, 37(5), 413-434. doi:10.18023/kjece.2017.37.5.018

Chung, O. B. (2002). Children development. Seoul: Hakjisa.

Chung, O. B. (2006). Baldalsimlihag: Jeonsaeng-ae inganbaldal [발 달심리학: 전생애 인간발달]. Seoul: Hakjisa.

Chung, O. B., \& Chung, S. H. (2019). Parent education (3rd ed.). Seoul: Hakjisa.

Hur, Y. (2006). Abeoji-ui yang-yughaengdong-e gwanhan yeongu [아버지의 양육행동에 관한 연구]. Educational Research, 26(1), 97-116.

Hwang, H. S., \& Suh, J. H. (2018). The effects of preschoolers temperament on peer play behaviors: Focusing on mediation of mothers social interaction parenting behaviors. Korean Journal of Childcare and Education, 14(1), 249-268. doi:10.14698/jkcce.2018.14.01.249

Hwang, Y.-S., \& Choi, M.-S. (2007). The analysis on the causal model between playfulness, temperament, and social competence of young children. The Journal of Korea Open Association for Early Childhood Education, 12(2), 49-66.

Jang, H. E., \& Kim, C. K. (2018). Mediation effects of father's parenting behavior in the influence of infant's temperament to children's affective problems: Latent growth curve modeling and autoregressive cross-lagged modeling. The Korea Association of Child And Education, 109, 21-52. dol:10.37918/kce.2018.03.109.21

Jo, E. O., \& Choe, Y. H. (2003). A study of children's temperament and play behavior. Korean Journal of Play Therapy, 6(1), 5767.

Kang, J. H., \& Lee, K. N. (2011). Effects of children's individual variables and maternal parenting on children's playfulness. Jounal of Korean Child Care and Education, 7(2), 159-180.

Kim, H.-H., \& Kim, S.-Y. (2020). Exploring the possible direction of interpreting inconsistent mediational effect. Korean Jounal of Psychology: General, 39(1), 91-115. doi:10.22257/ kjp.2020.3.39.1.91

Kim, I. (2017). Yua baldal-eul wihan bumoyeoghalgwa bumogyoyug gaeseonbanghyang [유아 발달을 위한 부모 역할과 부모교육 개선방향]. KDI FOCUS, 79, 1-6.

Kim, J. H. (2017). Parenting involvement of fathers in infancy and pervasive development problems of five-year-old children (Master's thesis). Retrieved from http://www.riss.kr/link?id $=\mathrm{T} 14462451$

Kim, J. (2017, December 21). Dowajuneun appa NO! hamkkehaneun appa YES! bigdeiteolo bon appa yug-a [도와주는 아 빠 NO! 함께하는 아빠 YES! 빅데이터로 본 아빠 육 아]. Daehanmingugjeongchaegbeuliping [대한민국정책 
브리핑]. Retrieved from https://www.korea.kr/news/ pressReleaseView.do?newsId=156253124

Kim, J. W., \& Lee, M. J. (2007). The print richness of early childhood classroom. Korean Journal of Child Studies, 28(3), 101-113.

Kim, K. S., \& Park, I. J. (2002). The relationship between fathers' rearing behaviors, playfulness, and young children's playfulness. Korean Journal of Play Therapy, 5(2), 27-43.

Kim, S. L., \& Park, C. H. (2015). Effects of young children's temperament, teacher efficacy, and teacher-child interactions on peer play interactions. Journal of Korean Child Care and Education, 11(6), 37-58. doi:10.14698/jkcce.2015.11.037

Kim, W., Kim, J., Lee, I., \& Nam, Y. (2014). A structural relationship study of young children's negative peer interaction behaviors and related variables. The Korean Society For Early Childhood Education, 34(2), 29-48. doi:10.18023/kjece.2014.34.2.002

Kim, Y. (2012). Abeojiui yug-acham-yeo, aileul haengbog-eulo ikkeuneun jogeon [아버지의 육아참여, 아이를 행복으로 이그는 조건]. KICCE Policy Brief, 4, 1-4.

Kwon, M. K., Moon, M., \& Kim, Y. (2019). A study on a paradigm shift towards a culture that respects parenting and raising positive awareness on parenting culture (1): Analysis and issues of parenting culture (Report No. 2019-26). Retrieved from http://repo.kicce.re.kr/handle/2019.oak/1766

Lasley, M. (2007). Understanding 4-5 year-olds (H. Lee, Trans.). Seoul: Sigmapress. (Original work publiched 2012).

Lee, C. R., \& Moon, H. J. (2011). Relationship of children's peer play behavior and mother's parenting self-efficacy and mother's perception of the father participation. Journal of Human Science, 31(1), 66-91.

Lee, H., \& Shin, Y. (2014). Cluster analysis of peer play behaviors of young children. The Korean Society For Early Childhood Education, 34(4), 55-73. dol:10.18023/kjece.2014.34.4. 003

Lee, J. H., \& Kim, H. Y. (2012). A study on variables related to positive and negative peer interactions of young children. Korean Journal of Childcare and Education, 8(6), 301-322.

Lee, K. (2021). SPSSwa AMOS hwal-yong-yeje-wa hamkke yu-agyoyug-yeonguleul wihan gogeubtonggye [SPSS와 AMOS 활 용예제와 함께 유아교육연구를 위한 고급통계]. Seoul: Hakjisa.

Lee, M. R. (2015). The effects of young children's temperament, parenting styles and teacher-child interactions on peer interactions. Journal of Korean Child Care and Education, 11(5), 191-214. doi:10.14698/jkcce.2015.11.191

Lee, S.-H., Lee, E.-G., \& Park, S.-Y. (2019). Warmth parenting and the social competence of preschoolers: Sequential mediation effects of self-esteem and positive peer play interaction. Journal of Korean Child Care and Education, 15(4), 37-57. doi:10.14698/jkcce.2019.15.04.037
Lim, H.-J. (2018). A study on a children' social competence via children' self-esteem, and peer-play interactions cluster analysis. Korean Journal of Early Childhood Education, 38(3). 215-236. doi:10.18023/kjece.2018.38.3.009

Ministry of Education., \& Ministry of Helath and Welfare. (2019). 2019 gaejeong nuligwajeong haeseolseo [2019 개정 누리과정 해설서](Report No. 11-1342000-000522-01). Retrieved from Ministry of Education website: https://moe.go.kr

Moon, H.-L., \& Ohm, J.-A. (2009). The relationships between the interactive peer play of male and female children and parents verbal control style. The Journal of Educational Studies, 40(2), 159-181.

Panel Study on Korean Children. (2012). Panel study of Korean children 5th survey [Data file and codebook]. Retrieved from https://panel.kicce.re.kr

Panel Study on Korean Children. (2013). Panel study of Korean children 6th survey [Data file and codebook]. Retrieved from https://panel.kicce.re.kr

Panel Study on Korean Children. (2014). Panel study of Korean children 7th survey [Data file and codebook]. Retrieved from https://panel.kicce.re.kr

Park, C., Kim, K. J., \& Choi, Y. K. (2018). 2018 yuagyoyng baljeoneul wihan seoulteugbyeolsigyoyugcheong-yuagyoyugjinheungwon-ui yeoghal jaegujohwa [2018 유아교육 발전을 위한 서울특별시교육청 유아교육진흥원의 역할 재구조화] (Report No. 2018-1). Retrieved from Korea Institute of Child Care and Education website: http://repo.kicce.re.kr/ handle/2019.oak/1580

Park, J.-Y., \& Lee, S.-H. (2009). Relationship between parenting attitude and children's playfulness. Korea Practice Association for Early Childhood Education, 14(1), 40-57.

Park, W. Y., Ma, J. S., \& Chon, E. Y. (2004). A study on the young children's playfulness and interactive peer play. The Journal of Korea Open Association for Early Childhood Education, 9(4), 285-298.

Rho, S. H. (2014). A study on the influence of the fathers' selfefficacy on the mothers' parenting stress: The mediation effect of parenting involvement. Korean Journal of Child Education and Care, 14(3), 45-59.

Shin, Y. L. (2019). Moderating effects of teacher-child relationship on the association between temperament and peer play interaction of young children. Korean Journal of Child Education \& Care, 19(2), 57-69. doi:10.21213/kjcec.2019.19.2.57

Song, J., \& Lee, S. (2017). The role of parents' child-rearing behavior and teacher-child interaction in peer interaction: The mediating role of social skills. The Korean Society For Early Childhood Education, 37(5), 507-531. doi:10.18023/ kjece.2017.37.5.022

Song, Y. J. (2017). Mediative effects of the children's temperament on the path from the mothers' rearing behavior to the 
children's interactive peer play. The Korean Society For Early Childhood Education, 37(2), 57-79. doi:10.18023/ kjece.2017.37.2.003

Suh, G. W. (2017). The influence of marital satisfaction on child's peer-play behavior and problem behavior: The mediated effects of fathers and mothers parenting behavior. Korean Journal of Child Studies, 38(6), 79-91. doi:10.5723/ kjcs.2017.38.6.79

Woo, S. J. (2016). The effects of parenting behavior and peer interaction on preschoolers' externalizing problem behaviors. Journal of Korean Child Care and Education, 12(2), 41-55. doi:10.14698/jkcce.2016.12.02.041

Yeon, E. M., \& Choi, H. S. (2014). Relationships among psychological characteristics of infant-father, parenting engagement and atitude, and young children's interactive peer play. Journal of Early Childhod Education \& Educare Welfare, 18(4), 229-251.

\section{ORCID}

Hee-Jin Yun http://orcid.org/0000-0001-6169-7460

Se-Jung Chun https://orcid.org/0000-0002-4259-6549

KyungOk Lee http://orcid.org/0000-0001-6270-2145

Received June 30, 2021

Revision received August 27, 2021

Accepted October 14, 2021 